\title{
Acculturation Preferences of the Turkish Second Generation in 11 European Cities
}

George Groenewold, Helga A.G. de Valk and Jeroen van Ginneken

Submitted unformatted final article version

(Submitted to Urban Studies (Sage Publications Ltd), August 2011; Published in the August 2014 issue)

\begin{abstract}
This article examines acculturation preferences of the Turkish second generation in 11 European cities and compares these with expectations of national society comparison group members. Multiple classification analysis (MCA) was used to examine the effects of city of residence, exposure to national society value system, cultural distance, social exclusion and neighbourhood quality on acculturation preferences. MCA was also applied to profile respondents according to background characteristics and dominant acculturation preference style, which is useful for both theory development and design of integration policies for specific target groups. Results show that the majority of the second generation maintain integration preferences, although subgroups with particular background characteristics such as low educational attainment, experiencing discrimination and living in a low-quality neighbourhood, maintain separation or marginalisation preferences. Contextual factors, notably city of residence, the proxy for national integration policy orientation, seemed more important in explaining acculturation preferences than individual-level factors.
\end{abstract}

Keywords: acculturation, children of immigrants, determinants, population studies/demography, social group, Turkish second generation, Western Europe

George Groenewold is at The Netherlands Interdisciplinary Demographic Institute, Lange Houtstraat 19, 2511 CV, The Hague, The Netherlands. Email: groenewold@nidi.nl.

Helga A.G. de Valk is at The Netherlands Interdisciplinary Demographic Institute, Lange Houtstraat 19, 2511 CV, The Hague, The Netherlands; and at the Vrije Universiteit Brussel, Pleinlaan 5, 1050 Brussels, Belgium. Email: valk@nidi.nl.

Jeroen van Ginneken was at The Netherlands Interdisciplinary Demographic Institute, Lange Houtstraat 19, $2511 \mathrm{CV}$, The Hague, The Netherlands. 


\section{Introduction}

Most immigrants in countries of the European Union (EU) concentrate in main urban areas. In 2010, the foreign born comprised 9.4 per cent of the total EU population, corresponding to 47 million people. Of these, about 31 million were born outside the EU and those from Turkey constitute the largest single origin group (European Commission, 2007a; Eurostat, 2011).

Fargues (2005) estimates that in 2004 about 2.7 million first-generation Turkish immigrants lived in the EU (plus Switzerland) and that the majority (70 per cent) live in Germany. Other important countries of residence are France ( 9 per cent), The Netherlands (7 per cent), Austria (5 per cent) and Switzerland (3 per cent). Much less is known on the size of the second generation, children born and raised in the EU with one or both parents born in Turkey. A few EU countries collect data permitting identification of the second generation of any immigrant group, but data access is often restricted by privacy laws. The Netherlands, though, publishes annual figures on the size of the first and second generation of immigrant groups (Statistics Netherlands, 2013). If the Dutch ratio of 1.81 (i.e. 1 st +2 nd generation/1st generation, 2003-05 period) is applied to other EU countries, the estimate for the entire Turkish community in Europe for 2004 would be 4.9 million persons, comprising 2.2 million second-generation Turks (see also Fargues, 2005).

Although the second generation in Europe has become of age and is becoming an important urban sub-population, still little is known of their attitudes and behaviour. Public debate on the integration of the second generation has meanwhile become a major issue in several countries. For instance, in the Netherlands, the country's multicultural policy is cited to have failed by referring to the high school drop-outs among secondgeneration Moroccan and Turkish students, and to the high unemployment and crime rates of the Moroccan second generation. In Germany, there is concern about the development of parallel societies whereby the Turkish second generation is oriented more on the Turkish community than on the wider German society. In France, the riots in banlieues, involving Algerian and Moroccan second-generation youth groups, pitched the cherished Republican model into crisis. Members of such youth groups face problems of identification and acculturation which are potentially related to incompatibility of immigrant group norms and values with those of the national society in which they grow up (Crul and Schneider, 2010).

At home, the second generation is raised in accordance with the value system in their parents' country of origin. Outside the home, they familiarise themselves with the national society's value system, while the kind of neighbourhood in which they live may be more or less conducive (for example, Mykyta et al., 2005). Acculturation expectations of the majority population towards immigrants contribute to the adoption of the national society value system because if such expectations are not met it may lead to social exclusion, stigmatisation and discrimination of the second generation (for example, Berry et al., 1977; Bourhis et al., 1997). Cultural distance between social groups - for instance, in terms of religion and religiosity may affect the sharing of norms, values and customs. Overall, the second generation seeks to balance norms and values maintained by the immigrant group and those of the national society and this may lead to acculturative stress and adaptation difficulties (Berry et al., 1989; Berry et al., 2006; Berry and Sabatier, 2010).

In this article, we examine acculturation preferences of the Turkish second generation living in 11 European cities. We com- pare their preferences with expectations of the national majority population, and investigate to what extent the preferences of the second generation are influenced by expo- sure to the national society value system, cultural distance, social exclusion and characteristics of the context in which they live. 


\section{Conceptualisation}

Initial theories of acculturation focused on first-generation immigrants, notably on Mexican and Asian immigrants in the United States. Their acculturation was viewed as a uni-directional process leading to assimilation whereby immigrants eventually think and act according to national society norms, values and customs (for example, Gordon, 1964). However, Glazer and Moynihan (1963) argued that a more pluralistic attitude, whereby the norms, values and customs of the immigrant group and those of the host society are negotiated according to the context, is also possible. In the 1990s, the theoretical focus in the US started capturing the second generation, such as in segmented assimilation theory (Portes and Rumbaut, 2001; Portes and Zhou, 1993) and other assimilation theories (Gans, 1992). These point to the different routes of assimilation into a society. For instance, the second generation may face downward assimilation into an urban underclass with permanent poverty as a distinct possibility, in particular those whose parents, due to poor language skills and limited knowledge of a new society, were unable to properly guide the integration of their children. Newer assimilation theories are more optimistic, in particular regarding the prospects of the third generation (Alba and Nee,

2003). A different line of research focuses on the psychological aspects of acculturation and can broadly be grouped into research on preferences, determinants and consequences of acculturation (Arends-Tóth and van de Vijver, 2006).

Acculturation preferences are addressed by Berry (1986) and colleagues (e.g. Bourhis et al., 1997; Navas et al., 2007). They argue that contact between national society populations and immigrant groups leads to adaptations in value systems of both groups.
Persons may choose to apply both national society norms, values and customs, and those of the immigrant group. Based on the choices people make Berry (1986, 1997, 2001; Berry and Sabatier, 2010) derived a typology classifying persons into four acculturation preference categories: assimilation, integration, marginalisation, separation. The assimilation category comprises people who mainly adhere to the national society value system to guide behaviour, while people in the integration category abide by both the national society and immigrant group value system. Persons in the separation category mostly refer to their immigrant group value system while those in the marginalisation category do not refer to either of the two value systems. Berry's typology derives from constructing two orthogonal intervallevel scales, one indicating preference for immigrant group norms, values and customs, the other indicating preference for those of the national society. Each scale or index is derived from combining the response of a set of Likert items. At their midpoints, derived from applying the median or mean split method, the scales are crossed, resulting in a quadrant comprising four acculturation preference categories (Donà and Berry, 1994).

This is illustrated in Figure 1. The $\mathrm{X}$ axis is labelled National Society culture Preference (NSP) index and $\mathrm{Y}$ axis Immigrant Group culture Preference (IGP) index. From the response on the Likert items, NSP and IGP values are derived, constituting $\mathrm{X}-\mathrm{Y}$ coordinates for each respondent, permitting positioning in Figure 1 and identification of an acculturation preference category. The distribution of respondents over categories can then be examined more closely. Should similar data become available in future, shifts in position can also be studied.

There is no agreed general theoretical model providing the determinants and mechanisms of acculturation, while empirical 


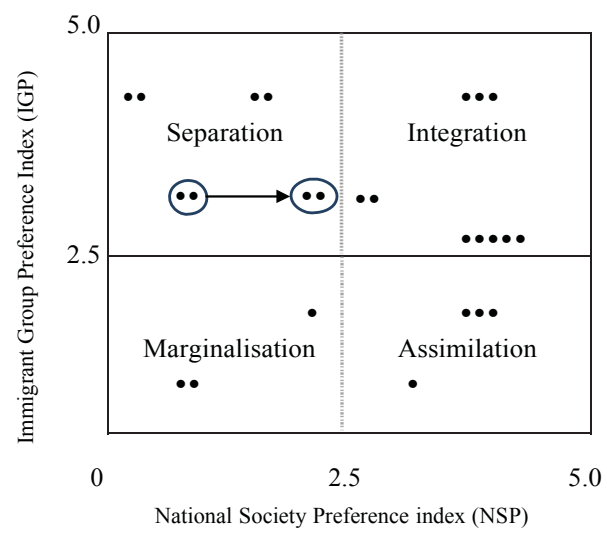

Figure 1. Classification of acculturation preferences and changing positions over time. Source: adapted from Berry (1986).

studies examine effects of a range of different determinants (Arentz-Tóth and van de Vijver, 2006). The interactive acculturation model (IAM) of Bourhis et al. (1997) is widely quoted though and stresses the importance of migration and integration policies in the formation of acculturation orientations in immigrant groups and national majority populations. Aspects of exposure to each other's value system, cultural distance and the cultural vitality of immigrant populations are also presented as determinants in the IAM model. Berry and colleagues (2006), among others, found that duration of residence, neighbourhood characteristics and experiencing discrimination impinge on the acculturation preferences of the second generation. In this article, we examine the effects of these determinants of acculturation.

Exposure to the national society value system transpires through the educational system where part of the socialisation of children occurs. At school, children of immigrants learn to speak the national society language, familiarise with the norms, values and customs of the country, and engage in intercultural contact. Higher educational attainment implies longer exposure to the
National society value system and to intercultural contact. Studies also indicate that higher educational attainment contributes to appreciation and cultivation of one's cultural heritage (for example, Odé and Veenman, 2003). In our study, we expect a higher educational attainment to be associated with both higher NSP and IGP scores.

Cultural distance reflects value system differences in places of origin and destination of immigrants and is revealed in religious affiliation and religiosity, among others. The Turkish second generation is predominantly raised according to Islamic traditions and maintains stronger religious beliefs than their peers in the national majority population. Studies show that immigrants and their offspring adapt more easily to a national society value system if religious tolerance and religiosity levels are similar and high. The latter applies to the context of Islamic communities in the US but less to such communities living in Europe. Although religious tolerance is high in Europe, religiosity levels are much lower than in the US and in countries of origin (for example, Bourhis et al., 1997; Foner and Alba, 2008; Pew Research Center, 2005). Overall, we expect that higher religiosity levels are associated with lower NSPscores and higher IGP scores.

Long-term exposure to discrimination, negative stereotyping and stigmatisation, at school, at work and in other contacts with members of the national society, may result in social and economic exclusion, in spatial segregation, in fostering ties between one's discriminated (in-group) and in rejection of the national society value system (for example, Alba and Nee, 2003). Eurobarometer research shows that twothirds of the EU population perceive that discrimination on the basis of ethnicity is widespread, and about one in two EU citizens perceives that discrimination on the basis of religion is widespread 
(European Commission, 2007b).We expect that a high level of exposure to discrimination is associated with lower scores on NSP and higher scores on IGP.

In addition to these person-level factors, contextual factors matter. Some studies (for example, Koopmans, 2010; Modood et al., 1997) find that spatial segregation along ethnic boundaries causes estrange ment of the national society value system. Yet other studies argue that it is the quality of the neighbourhood that matters rather than spatial segregation as such (for exam- ple, Mykyta et al., 2005). Immigrants living in neighbourhoods of 'concentrated disadvantage' generally have limited access to employment, good quality housing and education, and they perceive estrangement from the mainstream society and its value system. In neighbourhoods with high con- centration of immigrants, but where municipality and immigrant groups effectively co-operate and successfully upgrade housing and living conditions, immigrant com- munity members feel more engaged and show interest in the national society and its value system (for example, Sampson et al.,1997). We expect higher scores on NSP and equal or lower scores on IGP if persons perceive that the quality of their neighbour- hood is high.

The particular orientation of the national integration policy may also impinge on the acculturation preferences of members of immigrant communities, including the second generation. Integration policies reflect the delayed response of acculturation expectations of the majority population towards immigrants and their children (Berry, 2001; Berry et al., 1977; Bourhis et al., 1997). The orientations of integration policies of European countries differ. They reflect differences in attitudes of the national society populations towards immigrant groups regarding rights, entitlements and intercultural contact. The latter may be influenced by the origin countries of immigrants and shared history (for example, colonial relations).
For instance, Swedish and Dutch integration policies reflect the multiculturalist attitude of the national society population, granting immigrants cultural rights, access to welfare state entitlements and citizenship, protecting them against cultural discrimination. The Dutch policy orientation has been in transition since 2000, imposing stronger demands on immigrant communities regarding national society language skills, loyalty to the national society value system and religious tolerance. In the Germanspeaking countries, integration policies are far less inclusive. Immigrants and their children face higher barriers to citizenship and welfare state entitlements resulting in the emergence of parallel societies within a country's boundaries. The orientation of the French integration policy is directed towards assimilation, but in a different way than in the German-speaking countries. The French policy endorses equality and equal access to welfare state entitlements at the individual level, but discourages ethnic group and cultural diversity (for example, British Council and the Migration Policy Group, 2011; Crul et al., 2012).

It has been argued that a multiculturalist policy orientation leads to better integration of migrant communities because acceptance and tolerance of new cultural elements by a national society population would enhance the sharing of values and the social and economic participation of all people. This view has recently been challenged regarding the integration of first-generation immigrants. Koopmans (2010) presents evidence that first-generation Turkish and Moroccan immigrants in the Netherlands and Sweden, compared with those in German-speaking countries, exhibit lower levels of cultural adaptation, lower labour force participation and higher dependency on welfare state entitlements, and that they are more often in a socially or economically marginal position. A correlation can be expected between indicators of acculturation and national integration policy orientation yet little is known about the mechanism and 
direction of effects involved, notably regarding the second generation (Huschek et al., 2012). Although the implementation of national policies in cities of the same country may somewhat differ, we expect acculturation preferences in cities of the same country to be quite similar and different from those in city-pairs of other countries-notably, if national policy orientations are different.

\section{Data, Indicators and Methods}

\subsection{Data}

Survey data of the TIES (Integration of the European Second Generation) project were used. This study was designed to collect and analyse data on the second generation of three immigrant groups in 15 cities in 8 countries. Countries and cities were selected based on contrasting immigration, naturalisation and integration policies. Surveys were conducted in Austria, Belgium, France, Germany, Spain, Sweden and Switzerland and The Netherlands. Respondents are between 18 and 35 years old, born in the survey country with one or both parents born in Turkey, Morocco or the former Yugoslavia. A native comparison group in the same age range, born in the survey country out of parents born in the survey country was also included. In 2004, these survey countries comprised about 96 per cent of the Turkish second generation in EU countries plus Switzerland (Fargues, 2005).

Between June 2006 and December 2008, respondents were sampled and interviewed about issues such as educational attainment, labour market participation, cultural identity and preferences, discrimination, religion and migrant networks. In total, 500 respondents from each second-generation group and 500 respondents from the comparison group were interviewed in each country.
Comparison group members were sampled in the same neighbourhoods as the second generation.

Our study covers the Turkish second generation in 11 cities of the TIES survey: Amsterdam, Rotterdam, Paris, Strasbourg, Basel, Zurich, Linz, Vienna, Berlin, Frankfurt and Stockholm. In Dutch and Swedish cities, respondents were sampled from municipal population registers. In the German-speaking countries and France, access to the population register was not granted. Instead, a database of first, middle, surnames and other person information was compiled from data obtained from different institutions, such as electricity boards and phone companies. Using special screening software a sampling frame was derived permitting sampling of second- generation respondents. Native-born comparison group members were sampled using a random walk strategy whereby the addresses of sampled second-generation respondents served as a reference point (Groenewold and Lessard- Phillips, 2012).

Non-response rates were in the range of 40-60 per cent and not uncommon in surveys of immigrant groups in Europe (Stoop, 2005). Non-response bias was assessed using the response of interviewers on questions about how difficult it was to obtain information from each respondent. According to the continuum of resistance model (Lin and Schaeffer, 1995), difficult- to-reach respondents may serve as proxies for unobserved non-respondents. Easy and difficult-to-reach respondents appeared to differ regarding educational attainment and gender, permitting derivation of nonresponse weights. Sample design weights, population weights and non-response weights were combined and used in analyses to ensure that findings are, statistically speaking, representative for the Turkish second generation as a whole in these 11 cities (Groenewold and Lessard- Phillips, 2012). 


\subsection{Indicators}

The Immigrant Group culture Preference index (IGP) and the National Society culture Preference index (NSP) feature as the two dependent variables. Previous studies essentially followed three approaches to measure acculturation preferences: ranking preferences of the four acculturation categories using vignettes; assessing both preferences for immigrant group and national society values and then classifying respondents into four acculturation categories; and, simultaneous measurement of each acculturation preference style using distinct sub-scales (Ward and Rana-Deuba, 1999; Berry and Sabatier, 2010). In our study, IGP and NSP were derived using the second approach, using the responses on four Likert items about acculturation preferences. Subsequent to the introduction statement

"The integration of people of immigrant origin in (survey country) is an important topic in political debates and in the media", the question was posed "To what extent do you agree or disagree with the following statements?. (1) At home, people of immigrant origin have the right to live as much as possible in accordance with the cultural customs and norms of their parents' country of or region of origin; (2) At home, people of immigrant origin have the right to live as much as possible in accordance with the national cultural customs and norms in (survey country); (3) Outside the home, people of immigrant origin have the right to live as much as possible in accordance with the cultural customs and norms of their parents' country or of region of origin; (4) Outside the home, people of immigrant origin have the right to live as much as possible in accordance with the national cultural customs and norms in (survey country)". The phrasing of items means that the responses of the second generation can be interpreted as a projection of own acculturation preferences. Response categories are (1) totally disagree to (5) totally agree. Response analysis of questions (1) and (3) showed a high (rank) correlation, and so did the response analysis of questions (2) and (4). Thus, the responses on the same question pertaining to different domains appeared to be quite similar (for example, Berry et al., 2006). Therefore, the response on each pair of questions was summed, leading to an IGP scale based on questions (1) and (3) and a NSP scale based on questions (2) and (4). Values, ranging from 2 to 10 , were converted into Z-scores, and, for ease of interpretation, rescaled to a 0 to 5 range (McIver and Carmines, 1981). The mean split method was used to derive the midpoints on IGP and NSP scales.

In the models, age and sex feature as control variables to ensure that the interpretation of the effects of independent variables is not confounded by differences in age/sex composition. The following independent variables are included in the analyses.

First is the highest attained level of education, representing exposure to the national society value system. The ISCED coding Primary, Lower Secondary, Higher Secondary and Tertiary was used, after which Primary and Lower Secondary were merged.

A religiosity index, representing cultural distance was constructed from Likert items on: importance of being member of a particular religious group; importance of being a religious person; strength of affiliation with one's religious group; degree of similarity with members of one's own religious group; perceived personal relationship with God; religion as ultimate political authority; importance of expressing religious affiliation by showing religious symbols in public; and, importance given to Muslim women wearing a headscarf. Item response was measured on a five-point scale ((1) Totally agree, to (5) Totally disagree). Index scores were classified into three categories (low, medium, high).

An index of perceived discrimination, expressing exposure to social exclusion, was derived from seven Likert items on experience with discrimination in the domains of the school, neighbourhood, restaurants and other leisure-time destinations, encounters with police and with 
government institutions. Item response was measured on a five- point scale ((1) Never, to (5) Frequently). Index scores were classified into three categories (low, medium, high).

An index of perceived neighbourhood quality, based on seven Likert items measuring attachment to respondent's neighbourhood, contact with neighbours, contact with other people in the neighbourhood, liveability of the neighbourhood and perceived control of vandalism, crime and garbage in the neighbourhood. Item response was measured on a 5-point scale ((1) Totally agree, to (5) Totally disagree). Index scores were classified into three categories (low, medium, high). Content and interpretation of this index resembles Sampson's Social Cohesion and Trust Scale (Sampson et al. 1997).

City of residence was included to represent different national integration policy orientations. The acculturation preferences of the Turkish second generation may vary between city-pairs of countries with different policy orientations.

Indices of religiosity, perceived discrimination and neighbourhood quality were derived using the optimal scaling technique of categorical principal component analysis (CATPCA) (Linting et al., 2007). The reliability indicator (Cronbach $\alpha$ ) for the indices appeared to be 'good' to 'excellent' (i.e. larger than 0.70, Table 1).

\subsection{Methods}

Since we cannot a priori assume that a particular indicator has the same effect on both IGP and NSP we fitted independent models for IGP and NSP, using multiple classification analysis (MCA). MCA assumes interval-scale measurement of the dependent variable and nominal-scale measurement of independent variables. MCA fits an additive model to the data, without the need to make assumptions about the shape of the relation- ship between independents and a dependent.
The MCA statistical model (Andrews et al., 1973, p. 36) is

$$
Y_{i j \ldots n}=\bar{Y}+a_{i}+b_{j}+\ldots+e_{i j \ldots n}
$$

where, $Y_{\mathrm{ij} . . . n}=$ The score on the dependent variable $Y$ (NSP or IGP) of individual $n$ who falls in category $i$ of independent variable $A$, category $\mathrm{j}$ of independent variable $\mathrm{B}$, etc.; $\bar{Y}$ is the grand mean on the dependent variable $Y$ (NSP or IGP); $a_{i}$ is the 'effect' of members in the i-th category of independent variable $A ; b_{j}=$ The 'effect' of members in the $j$-th category of independent variable $B$; and $e_{i j . . n}$ is the error term for this individual.

Application of MCA leads to estimates of grand means of IGP and NSP respectively, and of estimates of deviations of grand means for all independent variable categories. These deviation-estimates can be summed and added to the grand mean estimates of IGP and NSP respectively, permitting the profiling of sub-groups with particular acculturation preferences and background characteristics. 
Table 1. Percentage distributions of model variables: Turkish second generation, by country and city (total percentages suppressed)

\begin{tabular}{|c|c|c|c|c|c|c|c|c|c|c|c|}
\hline & \multicolumn{2}{|c|}{ The Netherlands } & \multicolumn{2}{|c|}{ Germany } & \multicolumn{2}{|c|}{ Austria } & \multicolumn{2}{|c|}{ Switzerland } & \multicolumn{2}{|c|}{ France } & \multirow{2}{*}{$\begin{array}{c}\text { Sweden } \\
\text { Stockholm }\end{array}$} \\
\hline & Amsterdam & Rotterdam & Berlin & Frankfurt & Vienna & Linz & Zürich & Basle & Paris & Strasbourg & \\
\hline \multicolumn{12}{|l|}{ Controls } \\
\hline \multicolumn{12}{|l|}{$\overline{\text { Age }}$} \\
\hline $18-24$ & 51 & 53 & 40 & 44 & 66 & 54 & 59 & 62 & 75 & 53 & 41 \\
\hline $25-35$ & 49 & 47 & 60 & 56 & 34 & 46 & 41 & 38 & 25 & 47 & 59 \\
\hline Median & 24 & 25 & 26 & 26 & 23 & 25 & 24 & 23 & 23 & 25 & 26 \\
\hline \multicolumn{12}{|l|}{ Sex } \\
\hline Male & 46 & 51 & 56 & 40 & 43 & 50 & 50 & 53 & 49 & 39 & 49 \\
\hline Female & 54 & 49 & 44 & 60 & 57 & 51 & 51 & 47 & 51 & 62 & 51 \\
\hline \multicolumn{12}{|l|}{ Independents } \\
\hline \multicolumn{12}{|l|}{ Education } \\
\hline Primary + Low Secondary & 28 & 31 & 34 & 28 & 30 & 19 & 13 & 20 & 9 & 20 & 9 \\
\hline Upper Secondary & 43 & 42 & 60 & 65 & 56 & 57 & 72 & 68 & 34 & 49 & 66 \\
\hline Tertiary & 30 & 27 & 7 & 7 & 14 & 24 & 15 & 12 & 58 & 31 & 25 \\
\hline \multicolumn{12}{|l|}{ Religiosity (index) } \\
\hline Low & 9 & 6 & 23 & 15 & 9 & 25 & 23 & 29 & 17 & 10 & 16 \\
\hline Medium & 34 & 32 & 24 & 28 & 19 & 31 & 25 & 29 & 40 & 33 & 26 \\
\hline High & 58 & 62 & 54 & 57 & 73 & 45 & 52 & 41 & 44 & 57 & 58 \\
\hline Cronbach $\alpha$ & \multicolumn{2}{|c|}{0.92} & \multicolumn{2}{|r|}{0.94} & \multicolumn{2}{|c|}{0.93} & \multicolumn{2}{|c|}{0.91} & \multicolumn{2}{|r|}{0.92} & 0.90 \\
\hline \multicolumn{12}{|l|}{ Discrimination (index) } \\
\hline Low & 24 & 28 & 19 & 13 & 45 & 16 & 34 & 22 & 33 & 15 & 28 \\
\hline Medium & 27 & 24 & 27 & 31 & 14 & 12 & 28 & 32 & 37 & 31 & 19 \\
\hline High & 49 & 48 & 54 & 56 & 41 & 73 & 39 & 46 & 31 & 54 & 54 \\
\hline Cronbach $\alpha$ & \multicolumn{2}{|c|}{0.75} & \multicolumn{2}{|r|}{0.92} & \multicolumn{2}{|c|}{0.90} & \multicolumn{2}{|c|}{0.80} & \multicolumn{2}{|r|}{0.80} & 0.71 \\
\hline \multicolumn{12}{|l|}{ Neighbourhood quality (index) } \\
\hline Low & 30 & 31 & 26 & 34 & 29 & 38 & 37 & 31 & 39 & 41 & 41 \\
\hline Medium & 30 & 35 & 35 & 37 & 33 & 27 & 35 & 31 & 33 & 30 & 33 \\
\hline High & 40 & 35 & 39 & 30 & 39 & 35 & 27 & 39 & 28 & 30 & 26 \\
\hline Cronbach $\alpha$ & \multicolumn{2}{|c|}{0.70} & \multicolumn{2}{|c|}{0.77} & \multicolumn{2}{|c|}{0.85} & \multicolumn{2}{|c|}{0.73} & & 0.72 & 0.80 \\
\hline $\mathrm{N}$ & 237 & 263 & 253 & 250 & 252 & 206 & 206 & 248 & 248 & 252 & 251 \\
\hline
\end{tabular}




\section{Results}

Table 1 describes the characteristics of the respondents. The median age of Turkish second-generation respondents varies some- what between countries and is in the range of 23 to 26 years. Overall, the sex ratio is balanced, although women are slightly over- represented in Frankfurt and Strasbourg. In the majority of cities, upper secondary level of education is most common, but in Paris, Amsterdam and Rotterdam a considerable share of respondents attained a higher, tertiary, level. In most cities, the majority of the second generation maintains a high level of religiosity, notably in Vienna, and about half of the respondents perceive themselves to be very frequently exposed to various forms of discrimination. In Vienna, this is reported by almost three out of four respondents. In all cities, about equal proportions of secondgeneration Turks perceive that the quality of the neighbourhood in which they live is either low, medium or high. Secondgeneration Turks in Stockholm and Strasbourg are the most negative about neighbourhood quality.

Compared with second-generation Turks, native comparison group members (data not shown), are slightly older (about 2-4 years older), better educated (i.e. higher percentages with a tertiary educational attainment) and less religious, and they less often perceive themselves as being exposed to discrimination. Religiosity gaps between the two groups are most pronounced in Dutch, French and Swedish cities. Such gaps confirm results found in other studies (European Commission, 2005; Pew Research Center, 2005).

Table 2, based on NSP and IGP scores, shows how Turkish second-generation respondents distribute over Berry's four acculturation preference categories. In general, in most cities, the majority of the Turkish second generation maintains integration preferences and in Stockholm, Paris and Zurich considerable proportions (19-27 per cent) of the second generation also maintain assimilation preferences. In Vienna, a remarkably large share (44 per cent) position in the marginalisation category. In Amsterdam and Rotterdam more than one third of the Turkish second generation express separation preferences (34-39 per cent).

Table 2 also reveals acculturation expectations of native comparison group members towards immigrants and their offspring. Most native comparison group members expect people of immigrant origin to maintain integration preferences, which is reciprocated by the majority of the Turkish second generation. However, native comparison group members far more often expect the second generation to hold assimilation preferences. Compared with other cities, comparison group members in German and Swiss cities more often expect a marginalisation attitude of people of immigrant origin, which may express the view that people of immigrant origin should more often think of themselves as independent individuals rather than as a representative of an ethnic group (for example, Bourhis et al., 1997, p. 378). In light of the nation's tradition of multiculturalism, it is remarkable that a substantial share of the native comparison group in Dutch cities (27 per cent and 17 per cent) expect people of immigrant origin to maintain separation preferences.

Table 3 shows how selected background characteristics are linked to acculturation preferences. The top section of the MCA table presents estimates of grand means of NSP and IGP (i.e. 3.59 and 3.54 respectively) and the middle section presents estimates of deviations of the grand mean for all categories of control and independent variables. The bottom section comprises values of $R^{2}$, expressing the percentage of variation in NSP and IGP explained by independent and control variables. Contrary to the gross column estimates, the net column estimates describe the magnitude of effects after the effects of other model variables have been accounted for. 
Table 2. Percentage distribution of the Turkish second-generation and native comparison group members over acculturation preference styles, by country and city (total percentages suppressed)

\begin{tabular}{|c|c|c|c|c|c|c|c|c|c|c|c|}
\hline & \multicolumn{2}{|c|}{ Netherlands } & \multicolumn{2}{|c|}{ Germany } & \multicolumn{2}{|c|}{ Austria } & \multicolumn{2}{|c|}{ Switzerland } & \multicolumn{2}{|c|}{ France } & \multirow{2}{*}{$\begin{array}{c}\text { Sweden } \\
\text { Stockholm }\end{array}$} \\
\hline & Amsterdam & Rotterdam & Berlin & Frankfurt & Vienna & Linz & Zürich & Basle & Paris & Strasbourg & \\
\hline \multicolumn{12}{|l|}{ Turkish } \\
\hline Assimilation & 3 & 5 & 6 & 6 & 8 & 12 & 21 & 15 & 19 & 9 & 27 \\
\hline Integration & 62 & 53 & 83 & 81 & 42 & 74 & 59 & 64 & 67 & 75 & 67 \\
\hline Separation & 34 & 39 & 4 & 6 & 5 & 5 & 7 & 8 & 11 & 11 & 2 \\
\hline Marginalisation & 1 & 3 & 7 & 7 & 44 & 8 & 13 & 13 & 3 & 5 & 4 \\
\hline$n$ & 237 & 263 & 253 & 250 & 252 & 206 & 206 & 248 & 248 & 252 & 251 \\
\hline \multicolumn{12}{|l|}{ Native } \\
\hline Assimilation & 19 & 22 & 18 & 14 & 32 & 40 & 27 & 23 & 28 & 29 & 27 \\
\hline Integration & 52 & 59 & 56 & 64 & 58 & 48 & 57 & 59 & 59 & 63 & 70 \\
\hline Separation & 27 & 17 & 10 & 6 & 5 & 3 & 5 & 4 & 6 & 2 & 1 \\
\hline Marginalisation & 1 & 2 & 16 & 16 & 6 & 9 & 11 & 14 & 7 & 6 & 2 \\
\hline$n$ & 259 & 253 & 250 & 253 & 250 & 234 & 202 & 266 & 174 & 177 & 250 \\
\hline
\end{tabular}


Table 3. Effects of determinants on the National Society culture Preference index (NSP) and Immigrant Group culture Preference index (IGP), expressed as deviations of grand means of NSP and IGP $(\mathrm{N}=2666)$

\begin{tabular}{|c|c|c|c|c|}
\hline \multirow[b]{2}{*}{ Dependents } & \multicolumn{2}{|c|}{ NSP } & \multicolumn{2}{|c|}{ IGP } \\
\hline & & & \multirow{2}{*}{\multicolumn{2}{|c|}{3.54}} \\
\hline \multirow[t]{2}{*}{$\overline{\text { Grand mean }}$} & \multicolumn{2}{|c|}{3.59} & & \\
\hline & Gross & Net & Gross & Net \\
\hline \multicolumn{5}{|l|}{ Controls } \\
\hline \multicolumn{5}{|l|}{ Age } \\
\hline $18-24$ & -0.03 & 0.00 & -0.01 & 0.00 \\
\hline $25-35$ & 0.04 & 0.00 & 0.01 & 0.00 \\
\hline eta, beta & 0.03 & 0.00 & 0.01 & 0.00 \\
\hline \multicolumn{5}{|l|}{ Sex } \\
\hline Male & 0.02 & 0.01 & 0.05 & 0.03 \\
\hline Female & -0.02 & -0.01 & -0.04 & -0.03 \\
\hline eta, beta & 0.02 & 0.01 & $0.04^{*}$ & $0.03 *$ \\
\hline \multicolumn{5}{|l|}{ Independents } \\
\hline \multicolumn{5}{|l|}{$\overline{\text { City }}$} \\
\hline Amsterdam & -1.12 & -1.13 & 0.01 & 0.00 \\
\hline Rotterdam & -1.27 & -1.27 & -0.13 & -0.15 \\
\hline Berlin & 0.40 & 0.37 & 0.31 & 0.30 \\
\hline Frankfurt & 0.21 & 0.22 & 0.23 & 0.21 \\
\hline Vienna & -0.43 & -0.44 & -0.55 & -0.58 \\
\hline Linz & 0.48 & 0.47 & 0.34 & 0.33 \\
\hline Zurich & 0.08 & 0.10 & -0.30 & -0.27 \\
\hline Basle & 0.04 & 0.02 & -0.12 & -0.09 \\
\hline Paris & 0.18 & 0.19 & 0.07 & 0.14 \\
\hline Strasbourg & 0.29 & 0.30 & 0.24 & 0.23 \\
\hline Stockholm & 0.93 & 0.95 & -0.14 & -0.15 \\
\hline eta, beta & $0.54 * *$ & $0.54 * *$ & $0.25 * *$ & $0.25 * *$ \\
\hline \multicolumn{5}{|l|}{ Education } \\
\hline Primary + Low Secondary & -0.08 & 0.05 & 0.08 & 0.04 \\
\hline Upper Secondary & 0.04 & -0.03 & 0.00 & 0.01 \\
\hline Tertiary & -0.02 & 0.02 & -0.08 & -0.07 \\
\hline eta, beta & 0.04 & 0.03 & $0.05^{* *}$ & $0.04 * *$ \\
\hline \multicolumn{5}{|l|}{ Religiosity } \\
\hline Low & -0.25 & 0.03 & -0.19 & -0.21 \\
\hline Medium & -0.08 & -0.07 & -0.08 & -0.10 \\
\hline High & -0.03 & -0.01 & 0.10 & 0.11 \\
\hline eta, beta & $0.10^{*}$ & $0.04 *$ & $0.11^{* *}$ & $0.12 * *$ \\
\hline \multicolumn{5}{|l|}{ Discrimination } \\
\hline Low & -0.04 & -0.01 & -0.18 & -0.08 \\
\hline Medium & -0.02 & 0.02 & -0.03 & -0.05 \\
\hline High & 0.03 & 0.00 & 0.11 & 0.07 \\
\hline eta, beta & 0.03 & 0.01 & $0.11^{* *}$ & $0.06^{* *}$ \\
\hline
\end{tabular}


Table 3. (Continued)

\begin{tabular}{lcccr}
\hline \multicolumn{2}{c}{ NSP } & \multicolumn{2}{c}{ IGP } \\
\hline Neighbourhood quality & & & 0.10 & 0.07 \\
Low & 0.00 & -0.05 & -0.10 & -0.09 \\
Medium & -0.05 & -0.05 & -0.01 & -0.02 \\
High & 0.06 & 0.11 & $0.08^{* *}$ & $0.06^{* *}$ \\
eta, beta & $0.04^{* *}$ & $0.06^{* *}$ & & $9.0 \%$ \\
$\mathrm{R}^{2}$ & & $29.3 \%$ & & \\
\hline
\end{tabular}

Notes: * statistically significant at the 5 per cent level; ** statistically significant at the 1 per cent level.

Eta and beta indicate the relative importance of independent variables in explaining NSP and IGP, before and after the effects of other model variables have been accounted for.

Results in Table 3 confirm the expectation that the same independent variables may have different effects on the two dimensions of acculturation preference style, NSP and IGP. Furthermore, the independent variables are more important to explaining NSP ( 29 per cent) than IGP (9 per cent).

Eta and beta values indicate that place of residence is the single most important factor in the explanation of both NSP and IGP. Scores on NSP and IGP for cities of the same country are quite similar, which is according to expectation, with the clear exception of the Austrian cities. Only religiosity and neighbourhood quality are, statistically speaking, both important to the explanation of NSP and IGP, and effects are in the expected direction. For instance, low levels of religiosity and high neighbourhood quality are associated with a high preference for the national society value system. High religiosity level and low neighbour- hood quality are associated with a higher preference for the immigrant culture value system. IGP is also correlated with education and discrimination, but the effect of the educational attainment variable on IGP is in an unexpected direction because higher education seems to draw second-generation Turks away from the immigrant culture value system rather than reinforcing appreciation for it (for example, Odé and Veenman, 2003).

The predicted overall grand mean scores of NSP and IGP (3.59 and 3.54) confirm that on average the Turkish second generation in these 11 cities maintain integration preferences (see Table 2). MCA results show that this position applies to second- generation Turks in most cities, except to those in Rotterdam and Amsterdam. For Rotterdam, NSP and IGP scores are, respectively, $3.59-1.27=$ 2.32 and $3.54-0.15=3.39$, implying a position in the 'separation' quadrant. A similar finding applies to those living in Amsterdam. A closer look at the data of respondents in these two cities reveals that, compared with persons positioning in the 'integration' quadrant, per- sons in the 'separation' quadrant are more often persons with a low level of education, perceiving a high level of discrimination and living in low-quality neighbourhoods.

Results in the 'Net' columns can also be used for the profiling of sub-groups with particular background characteristics and 
acculturation preference styles. For instance, from the MCA results, it can simply be deduced that persons with a high preference for applying immigrant group norms and values (IGP) are generally men, living in Berlin, having a primary or lower secondary level of educational, are highly religious, perceive to be often discriminated against and living in lowquality neighbourhoods. Now what are the predicted scores on the NSP and IGP scales, and the implied dominant acculturation preference style for such persons? The predicted NSP co-ordinate for this kind of sub-group, counting category scores of non-statistically significant variables as zero, is 4.02 (i.e. $3.59+0.00$ $+0.37+0.00+0.01+0.00+0.11)$. The concomitant IGP score is 4.15 (i.e. $3.54+0.03+0.30+0.04+0.11+0.07$ +0.07 ). These two (NSP, IGP) co-ordinates position such persons in the 'integration' quadrant (Figure 1).

\section{Discussion}

Cultural orientations and preferences affect how people engage in intercultural relations, how they participate in the economy and how they believe the future of society should look. In recent decades, EU countries have turned into multi-ethnic societies so that integration of and social cohesion between ethnic groups has become an important policy goal. The integration and personal development of children of immigrants born and raised in EU countries - is of particular importance as they, together with national society peers, will shape the social and economic future of nations, including the migration and integration policies of the future. Therefore, research on the second generation is important. Some studies show that their performance in schools and in the labour market is not always at par with the majority of their population peers, and that lower performance may be related to psycho-social stress reflecting conflicts in cultural preferences and identity. In this article, we aim to contribute to a better understanding of the cultural preferences and identity of the second generation, in particular of the second generation of Turkish descent. We went beyond the mere classification of acculturation preferences by also exploring effects that certain personal and contextual factors have on preferences.

Measurement of acculturation was inspired by Berry's acculturation model. We derived a National Society culture Preference (NSP) index and Immigrant Group culture Preference (IGP) index. Scores on NSP and IGP were derived using survey data of the Turkish second generation in 11 European cities, permitting the identification and comparison of acculturation preferences across countries and cities. To examine the effects of determinants of acculturation preferences we used multiple classification analysis (MCA), a technique that also permits the profiling of sub-groups according to background characteristics and dominant acculturation preference style. The latter is not only useful for further theory development on the second generation, including factors and mechanisms shaping their values and views, but also for policy-makers seeking ways to identify target groups for tailored policies and programmes.

Results of our analysis reveal, first, that contextual factors - notably city of residence - are more important than individual-level factors in explaining acculturation preferences. Second, an unexpectedly high percentage of the Turkish second generation in Dutch cities hold separation preferences. Third, a high percentage of secondgeneration Turks in Vienna, and to a lesser extent in Swiss cities, maintain marginalisation preferences. And finally, a 
large gap exists between the preferences of second-generation Turks and the expectations of native comparison group peers, notably regarding assimilation.

The large explanatory effect of the variable city of residence indicates the importance of the context in which the second generation live, including the integration policy context. We found that acculturation preference styles in cities of the same country are indeed similar, and different from the styles observed in cities of other countries, except for Austria. There, preference styles of second-generation Turks living in Vienna and Linz are different. An explanation may be that the characteristics of the Turkish communities in Vienna and Linz are more different than in city-pairs of other countries. Schnell's (2012) results support this, in that there are important spatial differences in the composition of the Turkish community in Austria. Parents of second-generation Turks in Vienna mainly originate from less developed and more traditional provinces, while those in Linz mainly come from higher developed, more modern provinces. Compared with Turkish parents in Vienna, those in Linz may thus have raised their children more in the spirit of the national society value system, which could explain the higher preference for the integration style in Linz as compared with Vienna. If so, future migration and integration research should pay ample attention to potentially important social and cultural differences within the same ethnic community-notably, if such differences correlate with spatial differences in residence. Compositional differences, such as migrants' or parents' place of origin in the country of origin may help to improve explanations for the behaviour of the second generation, over and above person characteristics, the position of second generation in the society and the migration and integration policy context. In light of this, our study could not assess the role of ethnic group composition and interaction at the level of neighbourhoods within cities, including changes therein. Information on these issues would permit future research to get a better grip on the ways in which residential context impinges on acculturation preferences during the life course.

The finding that in all countries, except The Netherlands, a majority of the second generation position in the integration or assimilation quadrants, despite the differences in national integration policy orientations, is important. It suggests that differences in national integration policy orientation matter less to the formation of acculturation preferences of the second generation. The second generation are not migrants themselves, and, far more than their parents, they have been exposed to many facets of the national society. The integration policy context may matter more to the integration of first-generation immigrants, as suggested in earlier research (Koopmans, 2010). Issues of secondgeneration integration, including acculturation preference formation, may be much more shaped by welfare state policies and provisions than by integration policies per se (see Huschek et al., 2012). Future studies on the second generation should acknowledge this and include collection of country-specific information on welfare state indicators.

The remarkably high proportions of second-generation respondents in Dutch cities maintaining separation preferences deserve some attention as they seem counter-intuitive from the Dutch multiculturalist policy perspective before 2000 (Vermeulen and Penninx, 2000). A possible explanation for our findings could be that interviews were conducted in the aftermath of the assassination of Islam criticisers politician Pim Fortuyn and filmmaker Theo van Gogh, about 4 and 1.5 years before the survey respectively, and death threats to politician Ayaan Hirshi Ali for her stand against the position of women in Islam. These findings, though, 
are reasons for concern for policy-makers as they do reflect an undertow of feelings of mutual distrust reflecting cultural distance and lack of social cohesion in the society.

The relatively large proportion of secondgeneration Turks in Austrian (and Swiss) cities expressing marginalisation preferences might be related to the fact that immigrants, including children of immigrants born in these countries, must overcome many hurdles and many years of waiting before a permanent residence permit and citizenship come within reach. Years pass by to convince state, provincial and local officials about one's economic independence, native language skills and willingness to live according to the customs and norms of majority group Austrians and Swiss. There is no guarantee, though, that such efforts will lead to a permanent residence permit, let alone citizenship, as community representatives and neighbours have the right to vote against it (for example, British Council and the Migration Policy Group, 2011). After a long period of denial of one's cultural heritage and identity, it may be that a fair share of people of immigrant origin, including the Turkish second generation, conclude that maintaining a 'low profile' acculturation attitude and concealing strong opinions about acculturation in the open is the best 'survival' strategy. Persons having marginalisation preferences are of particular concern to policy-makers as they operate outside the arena of traditional social and ethnic groups in a society. Such persons are difficult to reach and influence with conventional communication strategies and social control mechanisms.

To conclude, the survey on which this article is based is the first one permitting comparison of the second generation of a major immigrant group in Europe with members of the national society, using comparable cross-sectional data and concepts.
We acknowledge that such data do have certain methodological limitations, including those related to causality. More specifically, our findings regarding the effects of perceived discrimination may be influenced by reverse causality in that per- sons holding separation preferences may be more likely to report discrimination experiences. In the absence of longitudinal data, models based on cross-sectional data cannot properly correct for this.

Bearing this in mind, several results are, however, worth the attention of policymakers. Measures stimulating educational attainment of the Turkish second generation will probably lead to lower attachment to Turkish group norms, values and customs, although they may not necessarily increase adoption of the national society value system. Measures counteracting discrimination and stigmatisation may pay off - not so much in terms of higher acceptance of the national value system, but more in terms of lowering preferences for applying immigrant group norms, values and customs. Measures to improve neighbourhood quality contribute to the adoption of national society norms, values and customs. The gaps found between the acculturation preferences of the secondgeneration Turks and the expectations of the national majority population in most countries are reason for concern to policymakers. Such gaps contribute to the emergence of parallel societies and a reduction of shared norms and values which may augment tensions between groups and further intolerance towards cultural and ethnic diversity.

\section{Acknowledgements}

Sadly, our colleague and co-author Prof. Dr. Jeroen van Ginneken passed away in December 2012. We would like to express our gratitude for his contribution in earlier versions of this article. 
Earlier preliminary versions were presented at the European Population Conference (2008) and the Population Association of America Annual meeting (2009). Comments and suggestions made at those occasions as well as those provided by the three anonymous reviewers are highly appreciated.

\section{Funding}

The contribution of the second author was part of, and funded by, the European Research Council Starting Grant project (no. 263829) "Families of migrant origin: A life course perspective".

\section{References}

Alba, R. and Nee, V. (2003) Bright vs. blurred boundaries: second-generation assimilation and exclusion in France, Germany, and the United States, Ethnic and Racial Studies, 28(1), pp. 20-49.

Andrews, F. M., Morgan, J. N., Sonquist, J. A. and Klem, L. (1973) Multiple classification analysis, 2nd edn. Institute for Social Research, University of Michigan.

Arentz-Tóth, J. V. and Vijver, F. J. R. van de (2006) Issues in conceptualization and assessment of acculturation, in: M. H. Bornstein and L. R. Cote (Eds) Acculturation and Parent-Child Relationships: Measurement and Development, pp. 33-62. Mahwah, NJ: Erlbaum.

Berry, J. W. (1986) Psychology of acculturation, in: J. Berman (Ed.) Nebraska Symposium on Motivation, Vol. 37, pp. 201-234. Lincoln, NE: University of Nebraska.

Berry, J. W. (1997) Immigration, acculturation, and adaptation, Applied Psychology: An International Review, 46(1), pp. 5-68.

Berry, J. W. (2001) A psychology of immigration, Journal of Social Issues, 57(3), pp. 615-631.

Berry, J. W. and Sabatier, C. (2010) Acculturation, discrimination, and adaptation among second generation immigrant youth in Mon- treal and Paris, International Journal of Inter- cultural Relations, 34, pp. 191-207.

Berry, J. W., Kalin, R. and Taylor, D. (1977) Multiculturalism and ethnic attitudes in Canada. Ottawa, Ontario: Supply and Services.
Berry, J. W., Trimble, J. and Olmeda, E. (1986) The assessment of acculturation, in: W. J. Lonner and J. W. Berry (Eds) Field Methods in Cross-cultural Research. London: Sage.

Berry, J. W., Kim, U., Minde, T. and Mok, D. (1987) Comparative studies of acculturative stress, International Migration Review,21, pp. 491-511.

Berry, J. W., Phinney, J. S., Sam, D. L. and Vedder, P. (Eds) (2006) Immigrant youth: acculturation, identity and adaptation, Applied Psychology: An International Review, 55(3), pp. 303-332.

Berry, J. W., Kim, U., Power, S., Young, M. and Bujaki, M. (1989) Acculturation studies in plural societies, Applied Psychology: An International Review, 38, pp. 135-186.

Bourhis, R. Y., Moise, L. C., Perreault, S. and Senecal, S. (1997) Towards an interactive acculturation model: a social psychological approach, International Journal of Psychology, 32(6), pp. 369-386.

British Council and the Migration Policy Group (2011) Migrant integration policy index (www. mipex.eu/; accessed 8 October 2012).

Crul, M. and Schneider, J. (2010) Comparative integration context theory: participation and belonging in new diverse European cities, Ethnic and Racial Studies, 33(7), pp. 1249-1268.

Crul, M., Schneider, J. and Lelie, F. (Eds) (2012) The European Second Generation Compared: Does the Integration Context Matter? Amsterdam: Amsterdam University Press.

Donà, G. and Berry, J. W. (1994) Acculturation attitudes and acculturative stress of central American refugees, International Journal of Psychology, 29(1), pp. 57-70.

European Commission (2005) Social Values, Science and Technology.Special Eurobarometer 225/Wave63.1, Brussels (http://ec.europa.eu/ public_opinion/archives/ebs/ebs_225_report_ en.pdf; accessed 8 October 2012).

European Commission (2007a) Europe's demographic future: facts and figures on challenges and opportunities. European Commission Directorate-General for Employment, Social Affairs and Equal Opportunities, Brussels.

European Commission (2007b) Discrimination in the European Union. Special Eurobarometer 263/Wave 65.4. Brussels (http://ec.europa.eu/ 
public opinion/archives/ebs/ebs 263 sum en. pdf; accessed 8 October 2012.

Eurostat (2011) Statistics in focus: 34/2011 (http:// epp.eurostat.ec.europa.eu/cache/ITY_OFFPUB/ KS-SF-11-034/EN/KS-SF-11-034-EN.PDF; accessed 8 October 2012).

Fargues, P. (2005) How many migrants from, and to, Mediterranean countries of the Middle East and North Africa? (http://cadmus.eui.eu/ handle/1814/11684; accessed 18 February 2013).

Foner, N. and Alba, R. (2008) Immigrant religion in the U.S. and Western Europe: bridge, or barrier to inclusion?, International Migration Review, 42(2), pp. 360-392.

Gans, H. (1992) Second-generation decline: scenarios for the economic and ethnic futures of the post-1965 American immigrants, Ethnic and Racial Studies, 15, pp. 173-192.

Glazer, N. and Moynihan, D. P. (1963) Beyond the Melting Pot. Cambridge, MA: MIT Press.

Gordon, M. M. (1964) Assimilation in American Life. New York: Oxford University Press.

Groenewold, G. and Lessard-Phillips, L. (2012) Research methodology, in: M. Crul, J. Schneider and F. Lelie (Eds) The European Second Generation Compared: Does the Integration Context Matter? Amsterdam: Amsterdam University Press.

Huschek, D., Valk, H. A. G. de and Liefbroer, A. C. (2012) Partner choice patterns among the descendants of Turkish immigrants in Europe, European Journal of Population, 28(3), pp. 241269.

Koopmans, R. (2010) Trade-offs between equality and difference: immigrant integration, multiculturalism and the welfare state in cross-national perspective, Journal of Ethnic and Migration Studies, 36(1), pp. 1-26.

Lin, I. F. and Schaeffer, N. C. (1995) Using survey participants to estimate the impact of nonparticipation, Public Opinion Quarterly, 59, pp. 236-258

Linting, M., Meulman, J. J., Groenen, P. J. F. and Kooij, A. J. van der (2007) Nonlinear principal components analysis: introduction and application, Psychological Methods, 12(3), pp. 336-358.

McIver, J. P. and Carmines, E. G. (1981) Unidimensional Scaling. London: Sage Publications.

Modood, T., Berthoud, R., Lakey, J., Nazroo, J. et al. (1997) Ethnic minorities in Britain: diversity and disadvantage - the fourth national survey of ethnic minorities. Policy Studies Institute, London.
Mykyta, L., Elo, E. T., Margolis, R. and Culhane, J. (2005) Neighbourhood characteristics: objective versus subjective measurement. Population Studies Centre, University of Pennsylvania and Department of Obstetrics and Gynaecology, Drexel University College of Medicine, Philadelphia.

Navas, M., Rojas, A. J., Garcia, M. and Pumares, P. (2007) Acculturation strategies and attitudes according to the relative acculturation extended model (RAEM): the perspectives of natives versus immigrants, International Journal of Intercultural Relations, 31(1), pp. 67-86.

Odé, A. and Veenman, J. (2003) The ethnocultural and socioeconomic position of ethnic minority groups in the Netherlands, in: A. Hagendoorn, L. Hagendoorn, J. Veenman and W. Vollebergh (Eds) Integrating Immigrants in the Netherlands: Cultural versus Socio-economic Integration. Farnham: Ashgate.

Pew Research Center (2005) An uncertain road: Muslims and the future of Europe (www. pewforum.org/Muslim/An-Uncertain-RoadMuslims-and-the-Future-of-Europe.aspx; accessed 10 January 2013).

Portes, A. and Rumbaut, R. (2001) Legacies: The Story of the Immigrant Second Generation. Berkeley, CA: University of California Press.

Portes, A. and Zhou, M. (1993) The new second generation: segmented assimilation and its variants, The Annals of the American Academy of Political and Social Science, 530(1), pp. 74 96.

Sampson, R. J., Raudenbush, S. and Earls, F. (1997) Neighbourhoods and violent crime: a multilevel study of collective efficacy, Science, 277, pp. 918-924.

Schnell, P. (2012) Educational Mobility of SecondGeneration Turks in Cross-national Perspective. Doctoral dissertation. University of Amsterdam.

Statistics Netherlands (2013) Statline database (http://statline.cbs.nl; accessed 6 February 2013).

Stoop, I. A. L (2005) The hunt for the last respondent: non-response in sample surveys. SCP Report No. 2005/8, The Netherlands Institute for Social Research, The Hague.

Vermeulen, H. and Penninx, R. (2000) Immigrant Integration: The Dutch Case. Amsterdam: Spinhuis Publishers.

Ward, C. and Rana-Deuba, A. (1999) Acculturation and adaptation revisited, Journal of Cross-Cultural Psychology, 30(4), pp. 422-444. 